\title{
Efisiensi Tiang Group Konfigurasi 2x2 Fondasi Helical Pile pada Tanah Gambut
}

\author{
Fadlan ${ }^{1}$, Ferry Fatnanta ${ }^{2}$, Muhardi $^{3}$ \\ ${ }^{1}$ Mahasiswa Magister Teknik Sipil Universitas Riau, Jl. HR Subrantas Km 12,5 Simpang Baru, Tampan Pekanbaru \\ ${ }^{2,3}$ Dosen Magister Teknik Sipil Universitas Riau, JI. HR Subrantas Km 12,5 Simpang Baru, Tampan Pekanbaru \\ Correspondence e-mail: donfadlan@gmail.com
}

\begin{abstract}
Abstrak. Fondasi jarang sekali dipakai tunggal (satu tiang) sering kali dipakai berkelompok yang terdiri dari 2 tiang maupun lebih, karena kapasitas dukung satu tiang saja terkadang tidak cukup untuk memikul beban kolom. Pemasangan fondasi helical pile dalam formasi dan jarak yang berbeda akan menimbulkan kapasitas dukung yang berbeda pada tanah gambut. Untuk itu diperlukan nilai koreksi terhadap kapasitas dukung kelompok tiang yang dinyatakan dengan efisiensi. Makalah ini bertujuan untuk menganalisis kapasitas dukung kelompok tiang helical pile konfigurasi 2x2 dengan variasi jarak antar tiang 1,5D, 2,0D, 2,5D, \& 3,0D pada tanah gambut, serta memperoleh nilai efisiensi dari kapasitas dukung dan dari formula Converse-Laberre. Dari hasil analisis diperoleh efisiensi tiang untuk jarak antar tiang 1,5D adalah 0,99 , jarak 2,0 D adalah 0,93, jarak 2,5D adalah 0,86, dan jarak 3,0D adalah 0,79. Efisiensi yang diperoleh dari formula Converse-Laberre untuk jarak 1,5D adalah 0,44, jarak 2,0D adalah 0,56 , jarak $2,5 \mathrm{D}$ adalah 0,64 dan jarak $3,0 \mathrm{D}$ adalah 0,70 .
\end{abstract}

Kata kunci: Efisiensi tiang; Kapasitas Dukung Helical Pile; Tanah Gambut

Abstract. Installation of helical pile foundations in different formations and distances will provide different bearing capacities in peat soils. For this reason, a correction value to the bearing capacity of the pile group is required, which is stated with efficiency. This paper aims to analyze the bearing capacity of the helical pile group configuration $2 x 2$ with variations in the distance between the piles of $1.5 D, 2.0 D, 2.5 D, \& 3.0 D$ on peat soils, as well as obtaining the efficiency values from the bearing capacity and from the Converse-Laberre formula. The analysis shows the efficiency of the pile for the distance between the 1.5D pile is 0.99 , the distance of $2.0 \mathrm{D}$ is 0.93 , the distance of $2.5 \mathrm{D}$ is 0.86 , and the distance of $3.0 \mathrm{D}$ is 0.79 . The efficiency obtained from the Converse-Laberre formula for a distance of $1.5 \mathrm{D}$ is 0.44 , a distance of $2.0 \mathrm{D}$ is 0.56 , a distance of $2.5 \mathrm{D}$ is 0.64 and a distance of $3.0 \mathrm{D}$ is 0.70 .

Keywords: Bearing Capacity; Efficiency; Helical Piles

\section{PENDAHULUAN}

Tanah Gambut memiliki daya dukung yang kurang baik karna sifat kompresibilitas dan penurunan yang besar. Banyaknya lahan gambut di propinsi riau khusunya kota pekanbaru, menjadi tantangan tersendiri bagi para ahli geoteknik dalam mendesain perancangan struktur bawah (fondasi).

Fondasi merupakan bagian terendah dari bangunan yang meneruskan beban bangunan ke tanah atau batuan yang ada di bawahnya. Fondasi tiang banyak dipakai apabila beban bangunan cukup besar sedangkan tanah keras berada jauh di kedalaman. Selama ini fondasi yang banyak dipakai untuk tanah gambut diantaranya adalah fondasi tiang tipe fondasi tiang bor, dan fondasi tiang pancang dan fondasi cerocok. Selain tipe fondasi tiang tersebut dikenal juga fondasi tiang berulir (helical pile) untuk tanah gambut.

Fondasi tiang jarang sekali dipakai tunggal (satu tiang) sering kali dipakai berkelompok yang terdiri dari 2 tiang maupun lebih karena kapasitas dukung satu tiang saja terkadang tidak cukup untuk memikul beban kolom. Pemasangan fondasi helical pile dalam formasi dan jarak yang berbeda akan menimbulkan kapasitas dukung yang berbeda. Hal ini dikarenakan faktor penyebaran tegangan di sekeliling tiang yang saling tumpang tindih. Untuk itu diperlukan nilai koreksi terhadap kapasitas dukung kelompok tiang yang dinyatakan dengan efisiensi. Berdasarkan uraian di atas, maka rumusan rmasalah dalam penelitian ini adalah seberapa besar pengaruh jarak antar tiang terhadap efisiensi daya dukung kelompok helical pile konfigurasi 2x2 pada tanah gambut. Tujuan Penelitian adalah untuk mendapatkan prakiraan kapasitas dukung kelompok fondasi helical pile pada tanah gambut, dan memperoleh nilai efisiensi group tiang konfigurasi $2 \times 2$ fondasi helical pile.

\section{Tinjauan Pustaka Helical Pile}

Fondasi tiang helical adalah fondasi tiang yang terbuat dari baja fabrikasi yang terdiri dari satu atau lebih plat helical yang di instalasi dengan cara memutar fondasi tersebut kedalam tanah Dipandang dari proses pemasangan fondasi helical termasuk dalam kategori mudah, cepat, dan efisien. Untuk penanaman fondasi helical, para ahli kontruksi membutuhkan mesin hidrolik untuk memutar tiang searah jarum jam. Apabila fondasi helical ingin dibuka, maka para pekerja hanya perlu memutar tiang berlawanan arah jarum jam. Pemasangan fondasi helical tidak menghasilkan efek samping seperti: getaran dan suara pada metode hammer pile dan limbah air atau tanah pada metode bore pile. Selain itu daya dukung fondasi bisa diukur secara langsung melalui konversi torsi yang dihasilkan saat memutar fondasi helical. Fondasi helical pile bisa digunakan untuk menahan gaya tekan dan tarik. Untuk menghitung kapasitas dukung fondasi helical pile Perko (2009) menyarankan metode berikut :

\section{Metode Individual Bearing}

Metode Individual bearing mengasumsikan daya dukung helical pile terdiri dari dua tahanan, yaitu daya dukung tanah di bawah masing-masing plat helical dan adhesi (skin friction) antara kulit tiang dengan tanah. 
Berdasarkan asumsi tersebut maka dapat dibuat suatu persamaan daya dukung fondasi helical berdasarkan metode individual bearing.

$P u=\sum_{n} q_{u l t n} \cdot A_{n}+\alpha H(\pi d)$

Dimana :

$\mathrm{q}_{\text {ultn }}=$ Tekanan dukung di bawah plat

helical ke - n (kPa)

$\mathrm{A}_{\mathrm{n}} \quad=$ Luas plat helical ke- $\mathrm{n}\left(\mathrm{m}^{2}\right)$

$\alpha=$ Adhesi antara tanah dan tiang (kPa)

$\mathrm{H}=$ Panjang dari muka tanah sampai plat helical paling atas $(\mathrm{m})$

\section{Metode Cylindrical Shear}

Saat fondasi helical pertama kali ditemukan, metode individual bearing selalu dijadikan acuan dalam menghitung kapasitas daya dukung. Mooney dkk (1985) merekomendasikan model cylindrical untuk memprediksi daya dukung aksial fondasi helical. Metode cylindrical shear mengasumsikan seluruh volume tanah di antara plat termobilisasi satu-kesatuan menjadi bentuk slinder. Daya dukung cylindrical shear merupakan perpaduan antara daya dukung ujung di bawah plat paling dasar, kuat geser yang terbentuk oleh slinder tanah dengan tanah, dan adhesi kulit tiang dengan tanah. Berdasarkan mekanisme tersebut, metode cylindrical shear dirumuskan melalui persamaan berikut :

$$
P u=q_{u l t 1} \cdot A_{1}+T(n-1) s \pi D_{a v g}+\alpha H(\pi d)
$$

\section{Dimana :}

$\mathrm{q}_{\text {ult1 }}=$ Tekanan dukung di bawah plat helical paling bawah (kPa)

$\mathrm{A}_{1} \quad=$ Luas plat helical paling bawah $\left(\mathrm{m}^{2}\right)$

$\mathrm{T} \quad=$ Tegangan geser tanah $(\mathrm{kPa})$

$\alpha \quad=$ Adhesi $(\mathrm{kPa})$

\section{Kapasitas Dukung Kelompok Tiang}

Kapasitas kelompok tiang dipengaruhi oleh salah satu faktor berikut ini (Coduto,1994) :

a. Jumlah kapasitas tiang tunggal dalam kelompok tiang, bila jarak tiang jauh, atau

b. Tahanan gesek tiang yang dikembangkan oleh gesekan antara bagian luar kelompok tiang dengan tanah di sekelilingnya, jika jarak tiang terlalu dekat.

Pada tiang yang dipasang pada jarak yang besar, tanah di antara tiang tidak bergerak sama sekali, ketika tiang bergerak ke bawah oleh akibat beban yang bekerja. Tetapi, jika jarak tiang-tiang terlalu dekat, saat tiang turun oleh akibat beban, tanah di antara tiang-tiang juga ikut bergerak turun. Pada kondisi ini, kelompok tiang dapat dianggap sebagai tiang besar yang dibentuk oleh kelompok tiang dan tanah yang terkurung di dalamnya, dengan lebar yang sama dengan lebar kelompok tiang. Saat tanah yang mendukung beban kelompok tiang ini mengalami keruntuhan, maka model keruntuhannya disebut keruntuhan blok. Jadi, pada keruntuhan blok, tanah yang terletak di antara tiang bergerak ke bawah bersama-sama dengan tiangnya. Mekanisme keruntuhan yang demikian dapat terjadi pada tipe-tipe pancang maupun tiang bor.

\section{Daya Dukung Fondasi Dengan Beban Statis Tipe Constant Rate of Penetration (CRP)}

Pengujian daya dukung fondasi langsung di lapangan dapat dilakukan dengan beberapa metode, salah satunya adalah dengan memberikan beban statis pada fondasi dengan tipe prosedur constant rate of penetration (CRP). Prosedur Metode CRP adalah dengan membebani tiang secara terus menerus hingga kecepatan penetrasi ke dalam tanah konstan. ASTM 1143-81 memberikan standar kecepatan penurunan, yaitu 0,25 sampai $1,25 \mathrm{~mm} /$ menit untuk tanah kohesif dan 0,75 sampai $2.5 \mathrm{~mm} /$ menit untuk tanah granular. Pengujian dikatakan selesai apabila fondasi tidak menunjukkan peningkatan beban. Selain itu total penurunan telah mencapai $15 \%$ dari diameter tiang fondasi.

\section{Kurva Hubungan Beban Vs Penurunan}

Pengujian daya dukung fondasi menghasilkan kurva hubungan beban vs penurunan. Kurva beban vs penurunan dapat menunjukkan perilaku dan karakteristik ketahanan daya dukung suatu fondasi. Menurut Van Weele (1957) di dalam jurnal Thilakasiri (2006), ketika pertama kali fondasi menerima beban, skin friction memberikan tahanan daya dukung awal terhadap beban tersebut. Semakin beban meningkat, tahanan skin friction semakin memobilisasi beban sampai batas limitnya. Setelah tahanan ini menemui batas akhirnya, maka end bearing mulai memberikan reaksi tahanan secara linear sampai mencapai batas ultimate.

\section{Daya Dukung Ultimate Pada Penurunan $25 \mathrm{~mm}$}

Berdasarkan ASTM D1143-81, standar penurunan izin dari suatu fondasi adalah sebesar 1 inch $(25.4 \mathrm{~mm})$. Hal ini dapat diartikan, bahwa beban fondasi dari pengujian daya dukung pada penurunan $25 \mathrm{~mm}$ adalah daya dukung ultimate. Metode ini cocok digunakan pada tipe pengujian CRP (Constant Rate of penetration). Suatu pengujian daya dukung fondasi menghasilkan kurva hubungan beban vs penurunan. Pada penurunan $25 \mathrm{~mm}$ ditarik garis ke arah kurva. Kemudian dari titik pertemuan tersebut ditarik garis ke arah sumbu nilai beban, sehingga didapatkan daya dukung ultimate. Menurut Adeyeri (2015), total penurunan fondasi tidak boleh melebih dari 1 inch $(25.4 \mathrm{~mm})$. Hal ini untuk menghindari kerusakan pada struktur dan meningkatkan fungsi dari bangunan dalam segi kenyamanan.

\section{Efisiensi Kelompok Tiang}

Secara matematis, daya dukung grup tiang bisa dikatakan sebesar kapasitas daya dukung satu tiang dikalikan banyaknya tiang dalam satu grup tiang tersebut. Namun, perhitungan tersebut tidak berlaku dalam menentukan daya dukung grup tiang. Apabila pengaturan tiang-tiang yang membentuk suatu grup tiang telah memenuhi persyaratan, maka daya dukung grup tiang dapat didefinisikan sebagai besarnya kapasitas dukung satu tiang dikalikan jumlah tiang dalam satu grup dikalikan efisiensi grup tiang. Nilai pengali terhadap kapasitas dukung tiang tunggal dengan memperhatikan pengaruh kelompok tiang disebut efisiensi tiang (Eg). Efisiensi grup tiang dapat didefinisikan sebagai berikut : 
$E g=\frac{Q_{g}}{n Q_{u}}$

Dimana:

Eg = Efisiensi kelompok tiang

$\mathrm{Q}_{\mathrm{g}} \quad=$ Beban maksimum kelompok tiang yang mengakibatkan keruntuhan

$\mathrm{Q}_{\mathrm{u}}=$ beban maksimum tiang tunggal yang mengakibatkan keruntuhan

$n \quad=$ jumlah tiang dalam kelompok

Formula efisiensi tiang pada tanah pasiran :
a. Formula Sederhana
b. Formula Converse-Labarre
c. Formula Los-Angeles
d. Formula Seiler-Keeney
e. Formula Fled

\section{METODE PENELITIAN}

Secara umum penelitian ini terdiri dua kelompok yaitu pengujian laboratorium dan pengujian lapangan. Pengujian laboratorium yaitu pengujian terhadap propertis tanah gambut, sedangkan pengujian lapangan berupa pengujian tes pit, pengujian $C P T$, serta pengujian model fondasi helical pile. Pengujian model fondasi helical pile skala penuh dilakukan untuk mengetahui nilai kapasitas dukung serta untuk memperoleh nilai efisiensi.

\section{Lokasi Pengujian}

Pengujian pemodelan fondasi kelompok helical pile skala penuh di lakukan di lahan gambut jalan Datuk Setiamaharaja, Tasik Labuai, Bukit Raya, kota Pekanbaru provinsi Riau seperti ditampilkan pada gambar 1.

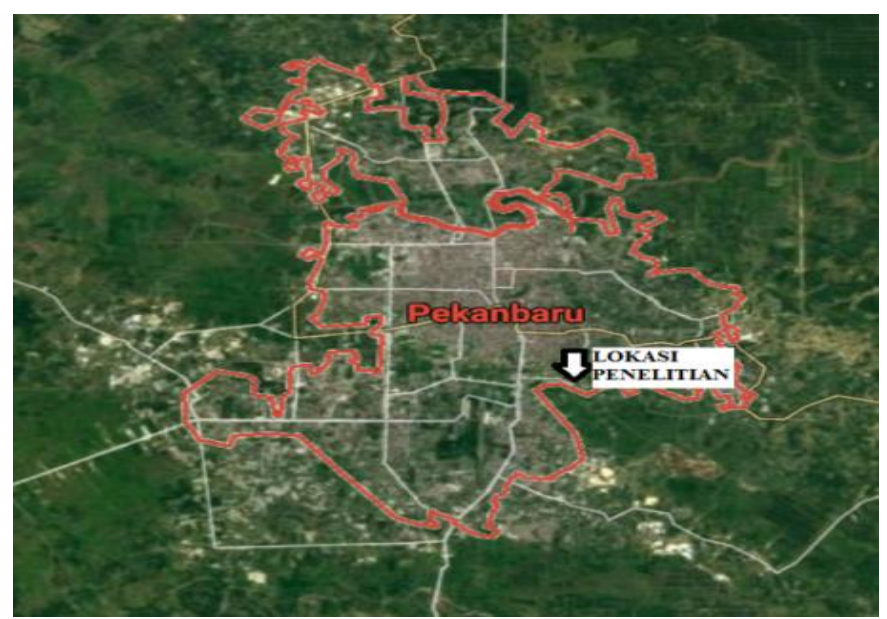

Gambar 1. Lokasi Penelitian

\section{Alat Pengujian}

Alat yang digunakan pada penelitian ini terdiri dari alat laboratorium dan alat lapangan, yaitu:

a. Alat laboratorium : Alat uji kadar air , alat uji kadar serat, alat uji kadar abu dan kadar organic, alat uji specific gravity, dan alat uji berat volume (unit weight)

b. Alat Lapangan : Alat CPT, Proving Ring, hydraulik Jack, Dial Gauge, Dial Penurunan dan Rangkaian portal uji beban. Tipe Fondasi helical yang digunakan adalah tipe LMS-30 seperti pada gambar 2 .

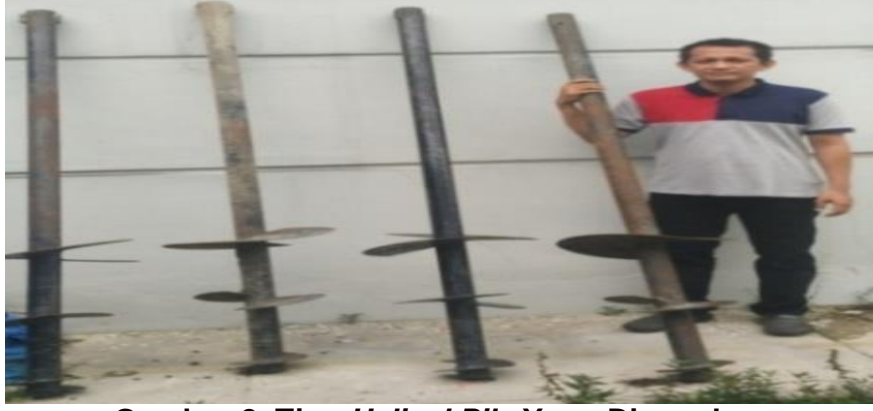

Gambar 2. Tipe Helical Pile Yang Digunakan

\section{Konfigurasi Tiang}

Pengujian pembebanan dilakukan terhadap model kelompok tiang fondasi helical pile konfigurasi 2x2 (empat tiang) seperti ditampilkan pada gambar 3. Variasi jarak tiang (S), jarak $1,5 \mathrm{D}$, jarak 2,0D, jarak 2,5D, dan jarak 3,0D dimana $\mathrm{D}$ adalah diameter pelat helical terbesar.



\section{Gambar 1. Konfigurasi 2x2 Fondasi Helical Pile}

\section{HASIL DAN PEMBAHASAN \\ Hasil pengujian propertis tanah gambut}

Berdasarkan hasil pengujian propertis gambut pada tabel 1 dan mengacu pada standar klasifikasi gambut ASTM 4427-92, maka klasifikasi gambut di lokasi penelitian digolongkan ke dalam Hemic peat dengan kadar serat 37,69\% (kadar serat di antara 33\% hingga $67 \%$ ) dan kadar abu 10,57\% tergolong kadar abu medium/medium ash peat (kadar abu diantara 5\% hingga 15\%) serta gambut yang mempunyai kadar air $714,55 \%$, daya serap air sedang/Moderately Absorben (300\% hingga $<800 \%)$.

Tabel 1. Hasil Pengujian Tanah Gambut

\begin{tabular}{|c|c|c|c|}
\hline Propertis Tanah Gambut & & Unit & Hasil \\
\hline Kadar air rerata $(w)$ & $(w)$ & $\%$ & 714,55 \\
\hline Berat Volume basah, $\gamma_{\text {wet }}$ & Ywet & $\mathrm{gr} / \mathrm{cm}^{3}$ & 1,10 \\
\hline Berat Volume basah, \wet t & $\gamma_{\text {wet }}$ & $\mathrm{kN} / \mathrm{m}^{3}$ & 10,75 \\
\hline Berat Volume kering, $\gamma$ dry & & $\mathrm{gr} / \mathrm{cm}^{3}$ & 1,45 \\
\hline Specific Gravity & & - & 1,43 \\
\hline Kadar Abu & & $\%$ & 10,57 \\
\hline Kadar organic & & $\%$ & 89,43 \\
\hline Kadar Serat & & $\%$ & 37,69 \\
\hline
\end{tabular}

\section{Kapasitas Dukung Hasil Pengujian Beban dilapangan}

Pengujian pembebanan fondasi helical pile $\mathrm{d}$ lapangan dilakukan terhadap tiang tunggal dan empat model kelompok tiang helical pile konfigurasi $2 \times 2$. Pengujian dilakukan dengan menggunakan metode Constan Rate Penetration. Hasil pengujian seperti ditampilkan pada Tabel 2. 
Tabel 2. Kapasitas Dukung Fondasi Helical Pile Hasil Pengujian Lapangan

Tipe Kelompok Tiang Intrepretasi Penurunan 25 mm

\begin{tabular}{lc} 
& $\mathrm{kN}$ \\
\hline Tiang Tunggal & 2,92 \\
4 Tiang 1,5 D & 11,55 \\
4 Tiang 2,0 D & 10,85 \\
4 Tiang 2,5 D & 9,98 \\
4 Tiang 3,0 D & 9,16 \\
\hline
\end{tabular}

\section{Analisa Efisiensi Group Tiang}

Efisiensi tiang diperoleh dari pengujian beban terhadap fondasi helical pile dilapangan dan dengan menggunakan formula Converse-Laberre.

a. Efisiensi Tiang Group Antara Pengujian Tunggal dan Kelompok

Efisiensi tiang yang di peroleh dari hasil pengujian lapangan fondasi kelompok helical pile dan pengujian tiang tunggal helical pile yang di kali jumlah tiang, diperlihatkan pada tabel 3.

Tabel 3. Nilai Efisiensi Pengujian Lapangan

Daya Dukung $(\mathrm{Kn})$

\begin{tabular}{|c|c|c|c|c|}
\hline \multirow[b]{2}{*}{ Variasi Tiang } & \multicolumn{2}{|c|}{ Daya Dukung (Kn) } & \multirow{2}{*}{$\begin{array}{c}\text { Pengujian secara } \\
\text { Tunggal x Jumlah Helical } \\
(\mathrm{nQu})\end{array}$} & \multirow[b]{2}{*}{ Nilai Efisiensi } \\
\hline & $\begin{array}{l}\text { Pengujian secara kelompok }(\mathrm{Qg}) \\
(\mathrm{kN})\end{array}$ & $\begin{array}{c}\text { Pengujian secara Tunggal } \\
(\mathrm{kN})\end{array}$ & & \\
\hline 4 Tiang 1.5D & 11,55 & & 11,67 & 0,99 \\
\hline 4 Tiang 2.0D & 10,85 & 2,92 & 11,67 & 0,93 \\
\hline 4 Tiang 2.5D & 9,98 & & 11,67 & 0,86 \\
\hline 4 Tiang 3.0D & 9,16 & & 11,67 & 0,79 \\
\hline
\end{tabular}

Pada tabel di atas nilai efisiensi terkecil diperoleh pada variasi 4 tiang $3,0 \mathrm{D}$ yaitu 0,79 dan nilai dan nilai efisiensi terbesar pada variasi 4 tiang $1,5 \mathrm{D}$ yaitu 0,99 .

b. Efisiensi Tiang Formula Converse-Laberre

Efisiensi tiang juga dihitung berdasarkan formula converse-laberre seperti pada tabel 4 :

Tabel 4. Nilai Efisiensi Formula Converse Laberre

\begin{tabular}{cc}
\hline Variasi Tiang & $\begin{array}{c}\text { Nilai Effisiensi } \\
\text { Converse-Laberre }\end{array}$ \\
\hline 4 Tiang 1,5D & 0,44 \\
4 Tiang 2,0D & 0,56 \\
4 Tiang 2,5D & 0,64 \\
4 Tiang 3,0D & 0,70 \\
\hline
\end{tabular}

Pada tabel di atas nilai efisiensi terkecil diperoleh pada 4 tiang $1,5 \mathrm{D}$ yaitu 0,44 dan nilai efisiensi terbesar pada 4 tiang $3,0 \mathrm{D}$ yaitu 0,70 .

c. Perbandingan Efisiensi Tiang Pengujian Lapangan Dan Efisiensi Tiang Formula Converse Laberre Dengan Penelitian Terdahulu

Efisiensi tiang dari hasil pengujian lapangan dibandingkan dengan efisiensi berdasarkan formula Converse-Laberre dan dengan penelitian terdahulu Septimarna (2016) seperti ditampilkan pada gambar 4.

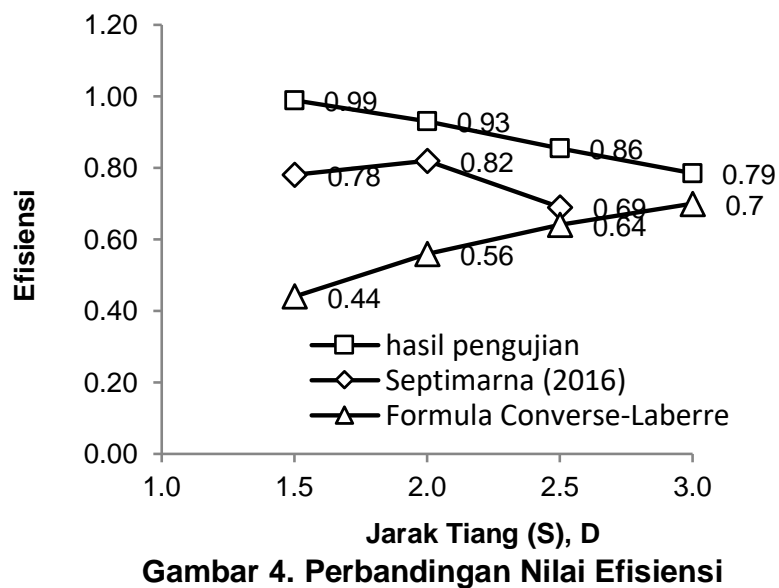

Efisiensi tiang dari hasil pengujian lapangan dan Septimarna (2016) menunjukkan pola nilai efisiensi yang mirip. Efisiensi dari pengujian lapangan akan menurun seiring bertambahnya jarak tiang, pada Septimarna (2016) nilai efisiensi mengalami kenaikan di jarak tiang $2,0 \mathrm{D}$ kemudian turun di jarak tiang 2,5D. Sedangkan pada formula Converse-Laberre nilai efisiensi akan meningkat seiring bertambahnya jarak tiang.

\section{SIMPULAN}

Dari hasil pembahasan diatas, dapat diambil

kesimpulan :

1. Hasil Pengujian tanah gambut di lokasi penelitian digolongkan pada jenis Hemic Peat dengan kadar abu medium ash peat dan daya serap air moderately absorbent.

2. Kapasitas Dukung Aksial pengujian beban di lapangan menghasilkan nilai terendah pada jarak $3,0 \mathrm{D}$ atau $105 \mathrm{~cm}$ yaitu $9,16 \mathrm{kN}$ dan tertinggi pada jarak $1,5 \mathrm{D}$ atau $52,5 \mathrm{~cm}$ yaitu $11,55 \mathrm{kN}$.

3. Nilai efisiensi kelompok tiang helical pile hasil pengujian beban lapangan berkisar 0,99 hingga 0,79. Efisiensi tiang akan menurun seiring bertambahnya jarak tiang.

4. Nilai efisiensi kelompok tiang helical pile perhitungan formula Converse-Laberre berkisar 0,44 hingga 0,70. Pada Efisiensi formula converse-laberre nilai efisiensi tiang akan meningkat seiring bertambahnya jarak tiang.

\section{DAFTAR PUSTAKA}

ASTM D1143-81. 1994. Standard Test Method For Piles Under Static Axial Compressive Load. United States of America: Annual Book of ASTM Standards sec 4.

ASTM D1997-91. 2001. Standard Test Method For Laboratory Determination of The Fiber Content of Peat Samples by Dry Mass. United States of America: Annual Book of ASTM Standards sec 4.

ASTM D2974-00. 2000. Standard Test Method For Moisture, Ash, and Organic Matter of Peat and Other Organic Soils. United States of America: Annual Book of ASTM Standards sec 4. 
ASTM D4427-92. 2002. Standard Classification of Peat Samples by Laboratory Testing. International Journal of the Physical Sciences. United States of America: Annual Book of ASTM Standards sec 4.

Coduto.D.P dkk.1994. foundation design principles and practices. Prentice- Hall inc., New Jersey.

Hardiyatmo,H,C. 2010. Analisis dan Perancangan Fondasi, Gajah Mada University press, Yogyakarta.

Perko Howard, 2009. Helical Piles (A Pratical Guide to Design and Installation). New Jersey : John Wiley \& Sons, Inc.

Thilakasiri, H. S., Abeyasinghe,R.M., Tennakoon, B. L.,2006. "Dynamic Testing of End Bearing Bored Piles in Sri Lanka", Annual Transactions of the Institution of Engineers, Sri Lanka. pp 85-95.

Septimarrna, V. 2016. Perilaku Fondasi Helical Pile Pada Tanah Gambut. Tesis. Universitas Riau. 